\title{
Assessment of Presence of Cardiovascular Disease in Relation to Smoking
}

\author{
Rajiv Arora ${ }^{1}$ \\ ${ }^{1}$ Associate Professor \& Chief Cardiologist, Department of Cardiology \& ICCU, Govt. Medical College/ Guru Nanak Dev Hospital \& Allied Hospitals Amritsar (Punjab) \\ 143001.
}

\section{Abstract}

Background: Smoking is a major risk factor for the development and progression of cardiovascular diseases. Thus, the present study investigates presence of cardiovascular disease in relation to smoking in people aged 45-50 years. Subjects and Methods: This cohort study was conducted among 40 people of age 45-50 years over the period of 6 months. All relevant clinical history was taken before the commencement of the study. Statistical analysis was done by using SPSS, version 15 (SPSS, Inc., Chicago, IL) and p $<0.05$ was considered statistically significant. Results: In our study total participants were 40 in which 27 were male and 13 were females. In our study 18 men were recent smoker and 9 were ex-smoker. In females 8 were recent smoker whereas 5 were ex-smoker. 13 recent and 5 ex-smoker men had cardiovascular disease whereas 7 recent and 5 ex-smoker women had cardiovascular disease. Conclusion: The results of this study reinforce that smoking is a significant factor in causation of cardiovascular disease. Thus, we have to make strategies for smoking cessation programs in the primary care setting.

Keywords: Smoking, Cardiovascular Diseases, Smoking Cessation.

Corresponding Author: Dr. Rajiv Arora, Associate Professor \& Chief Cardiologist, Department of Cardiology \& ICCU, Govt. Medical College/ Guru Nanak Dev Hospital \& Allied Hospitals Amritsar (Punjab) 143001.

Received: February 2019

Accepted: February 2019

\section{Introduction}

Tobacco is the only legally available consumer product which kills up to one in every two users when used as intended. ${ }^{[1]}$ Smoking kills over 650,000 people in the European Union every year. ${ }^{[2]}$ In addition to the role of smoking in cancer initiation and promotion, cigarette smoking accelerates atherogenic cardiovascular disease in both a dose- and a duration-dependent manner through several concurrent pathways. Smoking incites an immunologic response to vascular injury, described as oxidative stress leading to lipid peroxidation, endothelial cell dysfunction, and foam cell proliferation in the tunica media. ${ }^{[3,4]}$ Smoking is more common among men and in lower socioeconomic classes, appearing concomitantly with other harmful health behaviour. ${ }^{[5]}$ Men also have a two to five times higher risk of Cardiovascular disease. ${ }^{[6]}$ Thus, the present study was conducted to investigate presence of cardiovascular disease in relation to smoking in people aged 45-50 years.

\section{Subjects and Methods}

This cohort study was conducted among 40 people of age 45-50 years over the period of 6 months. Ethical considerations were taken. Written informed consent was taken from the participants. All relevant clinical history was taken before the commencement of the study. Statistical analysis was done by using SPSS, version 15 (SPSS, Inc., Chicago, IL) and $\mathrm{p}<0.05$ was considered statistically significant.

\section{Results}

Table 1: Distribution of gender who were smoker

\begin{tabular}{|l|l|l|}
\hline Gender & $\mathbf{N}(\%)$ & p-value \\
\hline Male & $27(67.5 \%)$ & $<0.05$ \\
\cline { 1 - 2 } Female & $13(32.5 \%)$ & \\
\cline { 1 - 2 } Total & $40(100 \%)$ & \\
\hline
\end{tabular}

Table 2: Distribution of smoking history

\begin{tabular}{|c|c|c|}
\hline Smoking history & Male & Female \\
\hline Recent Smoker & 18 & 8 \\
\hline Ex-smoker & 9 & 5 \\
\hline
\end{tabular}

\begin{tabular}{|l|l|l|l|l|}
\hline Table 3: Presence of cardiovascular disease in smokers. \\
\hline \begin{tabular}{l} 
Presence $\begin{array}{l}\text { Fardiovascular } \\
\text { disease }\end{array}$ \\
\cline { 2 - 5 }
\end{tabular} & $\begin{array}{l}\text { Recent } \\
\text { smoker }\end{array}$ & $\begin{array}{l}\text { Ex- } \\
\text { smoker }\end{array}$ & $\begin{array}{l}\text { Recent } \\
\text { smoker }\end{array}$ & $\begin{array}{l}\text { Ex- } \\
\text { smoker }\end{array}$ \\
\hline Yes & 13 & 5 & 7 & 5 \\
\hline No & 5 & 4 & 2 & 0 \\
\hline
\end{tabular}

In our study total participants were 40 in which 27 were male and 13 were females. [Table 2] show smoking history whether the smoker is recent or he/ she was a ex-smoker. In our study 18 men were recent smoker and 9 were ex- 
smoker. In females 8 were recent smoker whereas 5 were ex-smoker. [Table 3] shows the presence of cardiovascular disease. In the present study 13 recent and 5 ex-smoker men had cardiovascular disease whereas 7recent and 5 exsmoker women had cardiovascular disease.

\section{Discussion}

The mechanisms of underlying cigarette smoke-induced atherosclerosis, arterial thrombosis and their clinical manifestations as cardiovascular disease can be divided into several systemic pathways. First, reactive oxygen species induce cardiac remodelling, seen as left ventricular hypertrophy and atrial fibrosis, which increase the risk of stroke. ${ }^{[7]}$ Second, nicotine-stimulated release of adrenal medulla hormones modifies cardiac output by increasing heart rate, ventricular contractility and blood pressure, which might lead to cardiac ischaemia. ${ }^{[8]}$ Third, compounds in cigarette smoke expose smokers to myocardial ischaemia by causing deficient vasomotor functions, which is seen as thickening of the arterial wall and intima media, reduced ability to expand and contract vessels, as well as increased arterial stenosis. ${ }^{[9,10]}$ Thus, the present study was conducted to investigate presence of cardiovascular disease in relation to smoking in people aged 45-50 years. In our study total participants were 40 in which 27 were male and 13 were females. 18 men were recent smoker and 9 were ex-smoker. In females 8 were recent smoker whereas 5 were exsmoker. 13 recent and 5 ex-smoker men had cardiovascular disease whereas 7 recent and 5 ex-smoker women had cardiovascular disease.

Keto $\mathrm{J}$ et al concluded that the effect of past or present smoking on individual cardiovascular risk parameters such as blood pressure and cholesterol seems to be of clinically minor significance in people aged 46 years. In other words, smoking seems to be above all an independent risk factor for CVD in the working-age population. Quitting smoking in working age may thus reduce calculated CVD risk nearly to the same level with people who have never smoked. ${ }^{[11]}$ Mallaina $\mathrm{P}$ et al by the the prediction models demonstrated a high $\mathrm{CV}$ risk attributable to smoking. For instance, the SCORE model demonstrated that this study population of smokers compared to non-smokers. ${ }^{[12]}$

A study by Bakhru A et al shows that inflammatory markers may be more accurate indicators of atherosclerotic disease. The results suggest that the inflammatory component of cardiovascular disease resulting from smoking is reversible with reduced tobacco exposure and smoking cessation.

\section{Conclusion}

The results of this study reinforce that smoking is a significant factor in causation of cardiovascular disease. Thus, we have to male strategies for smoking cessation programs in the primary care setting.

\section{References}

1. World Health Organization: WHO Report on the Global Tobacco Epidemic: World Health Organization: WHO Report on the Global Tobacco Epidemic; 2008 [http://www.who.int/tobacco/mpower/en/]

2. European Heart Network: CVD Statistics. [http://www.ehnheart.org/cvdstatisticshtml]

3. Libby P, Ridker PM, Maseri A (2002) Inflammation and atherosclerosis. Circulation 105: 1135-1143.

4. Szmitko PEB, Wang CHM, Weisel RDM, Jeffries GAB, Anderson TJM, et al. (2003) Biomarkers of vascular disease linking inflammation to endothelial activation Circulation 108: 2041-2048.

5. Jha P, Peto R, Zatonski W, et al. Social inequalities in male mortality, and in male mortality from smoking: indirect estimation from national death rates in England and Wales, Poland, and North America. Lancet 2006;368:367-70.

6. Jousilahti P, Vartiainen E, Tuomilehto J, et al. Sex, age, cardiovascular risk factors and coronary heart disease: a prospective follow-up study of 14786 middle-aged men and women in Finland. Circulation 1999;99:1165-72.

7. Varela-Carver A, Parker H, Kleinert C, et al. Adverse effect of cigarette smoke and induction of oxidative stress in cardiomyocytes and vascular endothelium. Curr Pharm Des 2010;16:2551-8.

8. Benowitz NL. Cigarette smoking and cardiovascular disease: pathophysiology and implications for treatment. Prog Cardiovasc Dis 2003;46:91-111.

9. Pittilo RM. Cigarette smoking, endothelial injury and cardiovascular disease. Int J exp Pathol 2000;81:219-30.

10. Rahman MM, Laher I. Structural and functional alteration of blood vessels caused by cigarette smoking: an overview of molecular mechanisms. Curr Vasc Paharmacol 2007;5:276-92.

11. Keto J, Ventola H, Jokelainen J, et al. Cardiovascular disease risk factors in relation to smoking behaviour and history: a populationbased cohort study. Open Heart 2016;3: e000358. doi:10.1136/openhrt-2015-000358

12. Mallaina P, Lionis $\mathrm{C}$, Rol H, Imperiali R, Burgess A, Nixon M, Malvestiti FM. Smoking cessation and the risk of cardiovascular disease outcomes predicted from established risk scores: results of the Cardiovascular Risk Assessment among Smokers in Primary Care in Europe (CV-ASPIRE) study. BMC Public Health. 2013 Dec;13(1):362.

13. Bakhru A, Erlinger TP. Smoking cessation and cardiovascular disease risk factors: results from the Third National Health and Nutrition Examination Survey. PLoS medicine. 2005 Jun 28;2(6):e160.

Copyright: (C) the author(s), 2019. It is an open-access article distributed under the terms of the Creative Commons Attribution License (CC BY 4.0), which permits authors to retain ownership of the copyright for their content, and allow anyone to download, reuse, reprint, modify, distribute and/or copy the content as long as the original authors and source are cited.

How to cite this article: Arora R. Assessment of Presence of Cardiovascular Disease in Relation to Smoking. Asian J. Med. Res. 2019;8(1):ME01-ME02.

DOI: dx.doi.org/10.21276/ajmr.2019.8.1.ME1

Source of Support: Nil, Conflict of Interest: None declared. 